\title{
Executive function, mentalizing and humor in major depression
}

\author{
J. UEKERMANN, ${ }^{1}$ S. CHANNON,${ }^{2}$ C. LEHMKÄMPER,${ }^{1}$ M. ABDEL-HAMID,${ }^{1}$ \\ W. VOLLMOELLER, ${ }^{3}$ AND I. DAUM ${ }^{1}$ \\ ${ }^{1}$ Institute of Cognitive Neuroscience, Ruhr-University of Bochum, Germany \\ ${ }^{2}$ Department of Psychology, University College London, United Kingdom \\ ${ }^{3}$ Westfälisches Zentrum für Psychiatrie und Psychotherapie, Ruhr-University of Bochum, Germany \\ (Received November 13, 2006; Final Revision June 4, 2007; Accepted June 6, 2007)
}

\begin{abstract}
Major depression is associated with cognitive deficits including memory, executive functions, and affect perception, which have been linked to dysfunction of fronto-subcortical networks. However, little is known about social cognition on more complex socially relevant tasks, such as humor processing. In this investigation a computerized humor-processing task was administered to 27 patients with a diagnosis of major depression (Dep) and 27 healthy controls (HC). Theory of mind (mentalizing) and executive functions were also assessed. Both groups were similar in IQ, age, and gender. Depressed patients performed below the control group with respect to both affective and cognitive aspects of humor processing, and these were related to mentalizing and executive performance. Our findings suggest social cognition deficits in major depression. Ability to process humor and appreciate mentalistic perspectives may in turn influence social interactions and should be given consideration in therapeutic approaches to depression. (JINS, 2008, 14, 55-62.)
\end{abstract}

Keywords: Depression, Theory of mind, Executive, Humor, Social cognition, Mentalizing

\section{INTRODUCTION}

Major depression is associated with cognitive deficits including memory and executive impairment (Veiel, 1997; Zakzanis et al., 1998). These in turn have been linked to dysfunction of fronto-subcortical networks including the dorsolateral prefrontal cortex (DLPFC), the ventrolateral prefrontal cortex (VLPFC), the anterior cingulate cortex (ACC), the basal ganglia and the hippocampus (Brody et al., 2001). Another important feature of depression is impairment of social functioning (Levendosky et al., 1995), as revealed by decreased social interaction (Gotlib \& Lee, 1989) and reduced reward value associated with social interaction (Nezlek et al., 2000). The studies on social cognition in depression have been mainly based on the perception of affective stimuli (such as faces and prosody), and have suggested impairments of emotion perception in major depression (Lee et al., 2005; Mikhailova et al., 1996; Surguladze

Correspondence and reprint requests to: Jennifer Uekermann, Institute of Cognitive Neuroscience, Department of Neuropsychology, GAFO 05/607, Ruhr-University of Bochum, 44780 Bochum, Germany. E-mail: jennifer.uekermann@ ruhr-uni-bochum.de et al., 2004). Mood congruent bias in emotion perception (e.g. Surguladze et al., 2004) has been found to be associated with an unfavorable course of depression.

Theory of mind (mentalizing) refers to the ability to attribute mental states such as beliefs or intentions to other people in order to understand and predict their behavior (Premack \& Woodruff, 1978). Social neuroscience has recently started to investigate the neural mechanisms of mentalizing. For instance, Stuss et al. (2001) reported that frontal lobe lesions impaired the ability to infer mental states from others. In an imaging study by Gallagher et al. (2000) the mentalizing condition of a story and a cartoon task was associated with activation in the medial prefrontal cortex. Vollm et al. (2006) reported activation of the medial prefrontal cortex, temporoparietal junction and temporal poles. In summary, mentalizing is believed to be mediated by a network including the prefrontal and temporal cortex (see Singer, 2006).

So far, little is known about social cognition in major depression on more complex socially relevant tasks, such as false-belief or humor processing tasks. Doody et al. (1998) administered false belief tasks to patients with schizo- 
phrenia, learning disability, and affective disorders. Those who were depressed showed generally intact performance on false belief tasks. Kerr et al. (2003) reported impairments on second-order false belief tasks in bipolar-depressed patients. In addition, Inoue et al. (2004) presented a secondorder false belief task to patients with remitted depression, who met the criteria for mood disorders (bipolar and unipolar). Significant impairments were observed. The investigation of mentalizing in depression is of particular importance in the light of the findings of Inoue et al. (2006), who reported that patients with mentalizing impairments relapsed significantly more than patients without such deficits.

Humour processing has mainly been studied in the context of incongruity resolution theory. This theory proposes two stages of humor processing, incongruity detection and resolution. Incongruity detection involves the detection of an incongruous element. In this stage "the perceiver finds his expectation about the text disconfirmed by the ending of the joke" (Suls, 1972). The second stage involves the resolution of the incongruent element and can be interpreted as an "attempt to draw information or inferences that make a link or provide a fit between the initial body of the joke, cartoon, or situation and its ending" (Suls, 1983). Evidence for the two-stage model comes from developmental studies (Pien \& Rothbart, 1976; Shultz, 1972; Shultz \& Horibe, 1974; Shultz \& Pilon, 1973) as well as factor analysis of data from healthy adults (Ruch, 1981; Ruch \& Hehl, 1984, 1986).

Findings from lesion studies have suggested hemispheric asymmetries relating to incongruity detection and resolution (Bihrle et al., 1986; Brownell et al., 1983; Wapner et al., 1981), with incongruity detection linked to the left and resolution to the right hemisphere. In these studies, incongruity resolution theory has been investigated by the presentation of joke stems with different alternative endings. Participants were instructed to select the correct funny punchline. More recently, investigations have focused on the contribution of the prefrontal cortex to humor processing (Wild et al., 2003). Shammi and Stuss (1999) reported that patients with prefrontal lesions rated the jokes to be less funny and selected more nonsensical endings (i.e., those involving incongruity detection but no resolution). Heath and Blonder (2005) reported that patients with damage to the right hemisphere involving the frontal lobes responded less strongly to humor compared to patients with damage to the right hemisphere without frontal involvement. Imaging findings in normal participants have shown that jokes rated as being funny yielded activations in the medial PFC and in the cerebellum compared to non-funny jokes (Goel \& Dolan, 2001) suggesting the need for a separation of the cognitive and affective component of humor. The cognitive component of humor refers to the comprehension of humorous stimuli, whereas the affective component involves appreciation of the stimuli. The need for such a separation is also highlighted in recent investigations (Uekermann et al., 2007a).
Humour processing may be partly dependent on executive functions and mentalizing ability. Shammi and Stuss (2003) observed significant associations between humor processing, working memory and set shifting. Uekermann et al. (2006, 2007b) reported that executive functions and mentalizing were significantly correlated with humor processing.

To our knowledge, there are no studies to date examining mentalizing and humor processing in unipolar depression. This is of particular importance in the light of studies reporting a positive association between sense of humor and psychological health, and a negative association between sense of humor and psychological distress such as depression (Deaner \& McConatha, 1993; Thorson et al., 1997; Thorson \& Powell, 1994). The aim of the present study was to investigate the relationship between humor processing, mentalizing, and executive functions in major depression. Comprehension of a correct punchline requires ability to hold the joke context and punchline in working memory, to generate diverse meanings, to compare possible alternative meanings and to link them adequately to the joke context. In addition, ability to inhibit a dominant meaning and to switch to alternatives may also contribute to humor processing. Thus four executive components (inhibition, set shifting, working memory, and verbal fluency) were chosen for the assessment of executive functions.

Based on the investigations, which have shown executive and mentalizing deficits in major depression, (see above) and in the light of studies suggesting that mentalizing and executive functions are linked to humor processing (see above) patients with major depression were expected to show humor processing deficits.

\section{METHODS}

\section{Participants}

Fifty-four participants took part in the present investigation. All gave informed consent in accordance with the guidelines of the Declaration of Helsinki (Varga, 1984) and the study was approved by the Ethics Committee of the RuhrUniversity, Bochum, Germany. The first group (DEP) comprised 27 patients with a diagnosis of major depression (14 men and 13 women). All patients suffered from unipolar depression. Participants with major depression were inpatients in the Westfälisches Zentrum für Psychiatrie und Psychotherapie, Bochum. The second group (HC) included 27 healthy controls (14 men and 13 women). Major depression was diagnosed according to DSM-IV (Saß et al., 2003). Mean disease duration was $18.07(S D=11.21)$ months. Sixteen patients had no history of a previous depressive episode, and 11 patients had one previous depressive episode. Duration of current episode was 14.37 ( $S D=11.21$ ) months on average. Medication consisted of selective serotonin and noradrenaline reuptake inhibitors (Venlafaxine, Escitalopram, Sertralin; $n=6$ ), selective noradrenergic and serotonergic antidepressants (Mirtazapin; $n=4$ ), tricyclic 
antidepressants (Trimipramin, Opipramol, Clomipramin; $n=$ $4)$, lithium ( $n=2$ ) and neuroleptics (Olanzapin; $n=1)$. Exclusion criteria were a history of neurological diseases, head trauma, anoxia, psychotic symptoms, stroke, learning disability, and addictive and psychiatric disorders (except depression for the DEP group).

Related investigations by the authors (Uekermann et al., 2006, 2007b) were separate studies with no overlap of participants.

The proportion of males and females did not differ significantly between groups $\left(\chi^{2}=0.001 ; p=.60\right)$. The two groups did not differ significantly in age $(p=.922)$, education $(p=.101)$ or intellectual ability $(p=.135)$, assessed by the subtests "Similarities" and "Picture Completion" of the brief Wechsler Intelligence Scales (Dahl, 1986). As expected, the DEP group scored significantly higher on the Beck Depression Inventory (Beck, 1987) $(t$ (52) = -24.56; $p<.0001)$. Demographic variables, affect and IQ scores are shown in Table 1.

\section{Humour Processing and Mentalizing}

Humor processing was assessed on a computerized task (Uekermann et al., 2006) based on the paradigm used in the studies by Brownell et al. (1983) and Shammi and Stuss (1999, 2003). The task consists of 24 joke stems, presented one at a time on the screen. After reading one joke stem, four alternative endings are presented: The correct punchline (C) involves incongruity detection and resolution; the slapstick ending (S) involves incongruity detection, the illogical ending (I) involves incongruity detection only and the logical ending (L) provided a logical ending. Participants were asked to select the correct punchline (cognitive component of humor processing). For assessment of the affec-

Table 1. Demographic Data, general intellectual functioning, executive functions and affect (means and standard errors) in the two groups

\begin{tabular}{lcr}
\hline \hline & DEP & \multicolumn{1}{c}{ HC } \\
\hline N (ns) & 27 & \multicolumn{1}{c}{27} \\
Age (ns) & $37.85(2.35)$ & $37.56(1.86)$ \\
IQ (ns) & $108.62(2.47)$ & $113.39(1.93)$ \\
Education (years; ns) & $10.59(0.34)$ & $11.30(0.37)$ \\
Depression*** & $27.74(1.94)$ & $3.19(0.62)$ \\
Stroop test & & \\
$\quad$ Reading** & $32.92(1.37)$ & $26.32(0.68)$ \\
$\quad$ Naming* & $46.05(1.99)$ & $39.39(1.42)$ \\
$\quad$ Interference $*$ & $89.19(6.26)$ & $64.02(3.66)$ \\
Trail Making Test A (ns) & $33.22(2.49)$ & $28.24(1.50)$ \\
Trail Making Test B* & $83.46(9.60)$ & $58.28(4.59)$ \\
Number-letter task*** & $6.30(0.42)$ & $8.70(0.25)$ \\
Verbal fluency (semantic)** & $33.41(1.39)$ & $40.93(1.82)$ \\
Verbal fluency (alternate)*** & $20.37(0.76)$ & $25.70(0.56)$ \\
\hline \hline
\end{tabular}

Note. ns indicates that means are not statistically different; ${ }^{*} p<.05$; $* * p<.01 ; * * * p<.0001$ tive component of humor processing, the joke stem is presented again with each of the alternative endings. Participants are asked to rate on a four-point scale the funniness of each ending (not funny-very funny) and the logic of each ending (i.e., how well it fits with the story) (very badlyvery well).

After the logic ratings, two simple factual control (nonmentalistic) questions are given about the story to assess general comprehension, and three mentalistic questions are given to assess mentalizing. Analyses included the percentage of correct answers. The first mentalistic question referred to the perspective of one protagonist and the second to the perspective of a second protagonist. The third mentalistic question required comprehension of the correct funny punchline. Participants' responses were recorded and scored on a scoring system with 2 points for correct answers, 1 point for partially correct answers and 0 points for incorrect answers. The responses were rated by two independent raters. Intraclass correlation was $r=.95$. Disagreements were resolved by a third independent rater.

\section{Example of a Joke}

\section{Joke stem}

"Martin had just started his own company. When a visitor came into the office, Martin picked up the telephone. He pretended to be discussing a multi-million-pound deal. Eventually he put the phone down and said to the visitor: "Can I help you?"

\section{Alternative endings}

C, The visitor said: "Yeah, I've come to connect up your telephone."

I, The visitor said: "The color of this wallpaper matches my tie."

S, "Martin's chair suddenly collapsed and he fell on the floor."

L, "The visitor said: 'Yes, I'm looking for a job in your new company.",

\section{Non-Mentalistic Fact Questions}

(1) Was the company started by Brad?

(2) Did Martin work in an office?

\section{Mentalistic Questions}

(1) Why did Martin pick up the telephone and speak?

(2) What did the visitor think when he heard Martin speaking into the telephone?

(3) What did Martin think when the visitor said 'Yeah, I've come to connect up your telephone?' 


\section{Measures of Executive Function}

\section{Inhibition}

The ability to inhibit a dominant response was assessed by the Stroop Test (Bäumler, 1985), with three conditions. The first involves reading aloud color words as fast as possible (Reading). The second task requires naming the color of colored lines (Naming). In the third condition participants are asked to name the ink color of colored words printed in an incongruent color, such as "RED" in green ink (interference). Dependent variables are the time needed to complete the first, second and third subtest and the time to complete the interference condition, corrected for overall slowing (interference-naming/naming).

\section{Working memory}

To assess working memory a number-letter sequencing test based on the Letter-Number Sequencing subtest of the Wechsler Memory Scale (Wechsler, 1997) was administered. Sequences of letters and numbers are read aloud (e.g., 2-L4). Participants are asked to first repeat the numbers in ascending order, followed by the letters in alphabetical order (2-4-L). The number of correctly repeated sequences was scored.

\section{Set shifting}

Psychomotor speed and set shifting were measured by the Trail Making Test (Reitan, 1992). The first subtest involves drawing lines to connect numbers in ascending order (condition A). The second task involves alternating between numbers and letters in ascending order (e.g. 1-A-2-B). The dependent variable was the time to complete the first and second conditions, and a set shifting score corrected for overall slowing was also calculated (condition B - condition A)/condition A).

\section{Verbal fluency}

Verbal fluency was measured by two subtests of the Regensburger Word Fluency Test (Aschenbrenner et al., 2000). In the first task participants are instructed to produce as many surnames as possible (semantic condition). The second subtest requires alternating between names of sports and fruits (alternating condition). The dependent variable was the number of correct words in the first and second conditions.

\section{RESULTS}

\section{Humour Processing}

\section{Selection of endings from alternatives}

The data for the selection of endings from alternatives are shown in Table 2.
Table 2. Percentage of alternative choices number of correct control questions, funniness and logical ratings (means and standard errors) in the two groups

\begin{tabular}{|c|c|c|}
\hline & DEP & $\mathrm{HC}$ \\
\hline Percent of $\mathrm{C}$ choices* & $88.58(3.90)$ & $97.22(0.89)$ \\
\hline Percent of S choices* & $2.00(0.64)$ & $0.46(0.26)$ \\
\hline Percent of L choices (ns) & $8.18(3.16)$ & $2.16(0.75)$ \\
\hline Percent of I choices (ns) & $1.23(0.66)$ & $0.15(0.15)$ \\
\hline \multicolumn{3}{|c|}{ Funniness Ratings $(\max =96)$} \\
\hline Correct* $*$ & $54.07(3.42)$ & $68.81(2.22)$ \\
\hline Slapstick* & $28.15(1.73)$ & $33.22(1.71)$ \\
\hline Logical (ns) & $24.29(1.12)$ & $26.59(0.67)$ \\
\hline Illogical (ns) & $22.78(1.22)$ & $25.18(0.73)$ \\
\hline \multicolumn{3}{|l|}{ Logical Ratings $(\max =96)$} \\
\hline Correct* & $66.07(3.88)$ & $74.85(1.98)$ \\
\hline Slapstick (ns) & $33.29(1.72)$ & $37.74(1.45)$ \\
\hline Logical* & $44.44(3.48)$ & $55.93(3.80)$ \\
\hline Illogical* & $25.85(1.23)$ & $30.00(1.12)$ \\
\hline $\begin{array}{l}\text { Non-mentalistic questions } \\
\quad \text { (percent correct; ns) }\end{array}$ & $97.38(0.86)$ & $96.99(1.83)$ \\
\hline Mentalistic questions** & & \\
\hline (percent correct) & $69.00(2.56)$ & $79.08(1.90)$ \\
\hline
\end{tabular}

Note. ns indicates that means are not statistically different; $* p<.05$; $* * p<.01 ; * * * p<.0001$.

The DEP group selected significantly fewer correct funny punchlines than the HC group $(t(52)=2.16 ; p<.05$. This is shown in Figure 1.

They also selected significantly more slapstick endings $(t(52)=-2.22 ; p<.05)$ and tended to select more logical endings $(t(52)=-1.85 ; p=.07)$. The significant differences were confirmed by non-parametric analyses.

The data for the funniness ratings are shown in Table 2 . Statistical analyses of funniness ratings were restricted to trials on which correct alternatives were selected. The DEP group was found to rate the correct endings $(t(52)=3.61$; $p<.01)$ and slapstick endings $(t(52)=2.08 ; p<.05)$ as

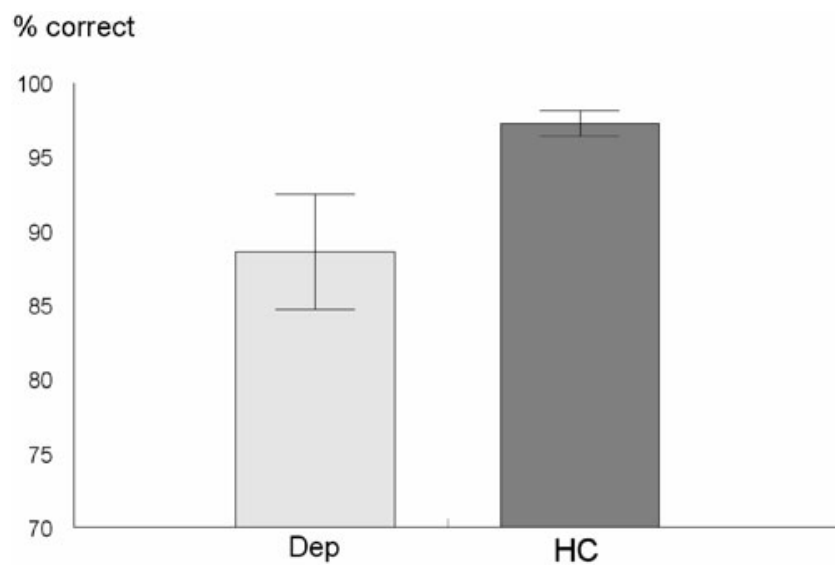

Fig. 1. Performance (means and standard errors) of the two groups in the humor processing task 
less funny than the HC group; they also tended to rate the logical alternatives as less funny $(t(52)=1.75 ; p=.08)$.

The data for the logical ratings are described in Table 2. Statistical analyses of logical ratings were also restricted to trials on which correct alternatives were selected. The DEP group rated the correct endings $(t(52)=2.01 ; p=.05)$, logical endings $(t(52)=2.23 ; p<.05)$ and illogical endings $(t(52)=2.49 ; p<.05)$ significantly lower than the HC group, and the slapstick endings also tended to be lower $(t(52)=1.92 ; p=.06)$.

The results for the mentalistic and non-mentalistic questions are shown in Table 2. There was no significant group difference for the non-mentalistic questions $(p=.85)$. For the mentalistic questions, DEP patients scored significantly below the HC participants $(t(52)=3.15 ; p<.01$. This is shown in Figure 2.

\section{Executive functions}

The results for the executive tests are described in Table 1.

\section{Working memory}

The DEP patients scored significantly below the HC group for correct number/letter sequences $(t(52)=4.96 ; p<$ $.0001)$

\section{Set shifting}

Repeated measures ANOVA for the TMT (A and B) revealed a significant group $\times$ condition interaction $F(1,52)=$ 5.16; $p<.05)$. Separate analyses of TMTA and TMTB showed that the DEP group was significantly slower for TMTB $(t(52)=-2.36 ; p<.05)$. No significant difference emerged for the TMTA $(p=.94)$ and the set shifting score corrected for overall slowing (condition B - condition A/condition A) $(p=.13)$.

\section{Inhibition}

Repeated measures ANOVA with condition and group as factors yielded a significant group $\times$ condition interaction

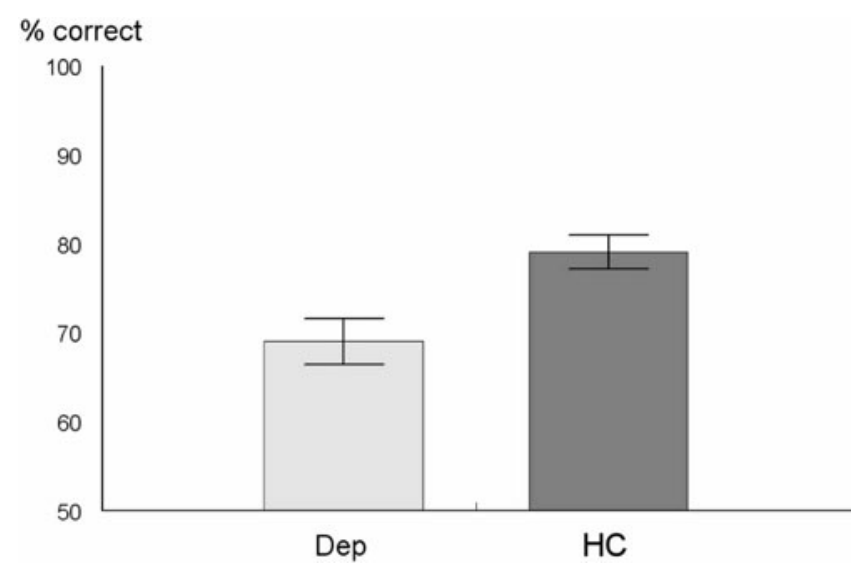

Fig. 2. Performance (means and standard errors) of the two groups in the mentalizing task
$(F(2,104)=9.59 ; p<.0001)$. Subsequent t-tests for the different conditions showed the DEP group to be significantly slower than the HC group for reading $(t(52)=-4.31$; $p<.001)$, naming $(t(52)=-2.73 ; p<.01)$ and the interference condition $(t(52)=-3.47 ; p<.01)$. In addition, analysis of the difference score corrected for overall slowing (interference-naming/naming) yielded a significant effect $(t(52)=-2.87 ; \mathrm{p}<.01)$, which was due to poorer performance by the DEP group in comparison with HC.

\section{Verbal fluency}

The DEP group produced significantly fewer items than the HC group for both the semantic $(t(52)=3.28 ; p<.01)$ and the alternating semantic task $(t(52)=5.65 ; p<.0001)$.

\section{Correlational Analyses}

The results for the correlational analyses are shown in Table 3.

Analyses for all participants revealed significant correlations between the number of correct punchlines and BDI scores $(r=-.34 ; p<.05)$; mentalizing scores $(r=.62 ; p<$ $.0001)$, working memory $(r=.38 ; p<.01)$ and verbal fluency tasks (both $p<.01$ ). The number of correct punchlines correlated significantly with inhibition $(r=-40$; $p<.01)$ and set shifting $(r=-.38 ; p<.01)$ scores corrected for overall slowing. In addition, funniness ratings for the correct punchlines showed significant associations with mentalizing $(r=.44 ; p<.01)$, alternating verbal fluency $(r=.50 ; p<.0001)$, working memory $(r=.40 ; p<.01)$ and inhibition $(r=.31 ; p<.05$. When correlations with mentalizing scores were examined, there were significant associations with BDI scores, working memory $(r=-.41$; $p=.002)$, both verbal fluency tasks $(r=.42 ; p<.01)$ and $r=.47 ; p=.0001)$, and set shifting $(r=-.36 ; p=.007)$.

\section{Multiple Regression Analyses}

Multiple regression analyses with the number of correct punchlines as the dependent variable and the BDI score as

Table 3. Results for the correlational analyses

\begin{tabular}{lccc}
\hline \hline & Num Co & Fun Co & MENT \\
\hline WM & $0.38 * *$ & $0.40 * *$ & $0.41 * *$ \\
INH & $-0.40^{* *}$ & $-0.31 *$ & $-0.25(\mathrm{~ns})$ \\
SET & $-0.38^{* *}$ & $-0.23(\mathrm{~ns})$ & $-0.36 * *$ \\
SVF & $0.36^{* *}$ & $0.34(\mathrm{~ns})$ & $0.42 * *$ \\
AVF & $0.55^{* *}$ & $0.50 * * *$ & $0.47 * *$ \\
BDI & $-0.34 *$ & $-0.52 * * *$ & $-0.41 * *$ \\
Num Co & 1 & $0.69 * * *$ & $0.62 * * *$ \\
Fun Co & $0.69 * * *$ & 1 & $0.44 * *$ \\
MENT & $0.62 * * *$ & $0.44 * *$ & 1 \\
\hline \hline
\end{tabular}

Note. WM, working memory; INH, inhibition; SET, Set Shifting; SVF, semantic verbal fluency; AVF, alternate verbal fluency; BDI, Beck Depression Inventory; Num Co, Number of correct punchlines; Fun Co, Funniness rating of the correct punchline; MENT, score in the mentaling task. NS $=$ not statistically significant; $* p<.05 ; * * p<.01 ; * * * p<.0001$. 
well as mentalizing as predictors yielded significant effects for mentalizing $(p<.0001)$. Separate regression analyses with the number of correct punchlines as dependent variable and BDI and each executive measure (set shifting, inhibition, working memory, and verbal fluency) as predictors revealed significant effects for set shifting and alternate verbal fluency (both $p<.05$ ). In addition, multiple regression analyses with the funniness ratings for the correct funny punchline as dependent variable and BDI as well as mentalizing as predictors showed significant effects for mentalizing $(p<.0001)$. Separate regression analyses with the funniness ratings for the correct funny punchline as dependent variable and BDI and each executive measure (set shifting, inhibition, working memory and verbal fluency) as predictors yielded significant effects for BDI and semantic verbal fluency (both $p<.05$ ). Multiple regression analyses with the number of correct punchlines as dependent measure and executive functions (set shifting, inhibition, working memory and verbal fluency) as well as mentalizing as predictors showed significant effects for mentalizing $(p<$ $.05)$, set shifting $(p<.05)$, verbal fluency $(p=.05)$ and a tendency towards significance for working memory $(p=$ .09). A further regression analysis including funniness ratings for the correct punchline as dependent variable and mentalizing as well as executive functions (set shifting, inhibition, working memory and verbal fluency) as predictors did not reveal any significant effects (all $p>.11$ ).

\section{DISCUSSION}

The aim of the present study was to investigate the relationship between mentalizing, executive functions, and humor processing in major depression. It was hypothesized that patients with major depression would show humor processing impairments and that these would be related to executive functions and mentalizing. The findings for the humor task showed that patients with major depression selected fewer correct punchlines, chose more slapstick endings and tended to select more logical alternatives. They also rated the correct and logical punchlines to be less funny than the control group. These results thus imply impairments with respect to cognitive and affective components of humor processing. Depressed patients also showed executive impairments as revealed by poorer performance on working memory, verbal fluency and inhibition tasks.

Previous investigations on social cognition in major depression have been mainly based on the perception of emotional faces and affective prosody. So far, little work has been carried out to investigate social cognition in major depression using more complex tasks. In these studies groups included mixed patients suffering from unipolar and bipolar disorders. To our knowledge this is the first study in which mentalizing and humor processing was investigated in unipolar depression. Humour has shown to be associated with psychological health, and a reduced sense of humor has been related to psychological distress such as depression (Deaner \& McConatha, 1993; Thorson \& Powell, 1994;
Thorson et al., 1997). Because humor-processing deficits in major depression may be because of mentalizing and executive deficits, the current findings may be of particular value for a more comprehensive understanding of the social behavior of patients with major depression.

Recent evidence has linked the frontal lobes to humor processing. Goel and Dolan (2001) suggested different brain circuits involving the PFC for the cognitive and affective components of humor processing. They compared semantic and phonological jokes that were rated as funny with jokes that were not, and reported activation in medial ventral PFC and bilateral cerebellum, which co-varied significantly with funniness ratings. In addition, the findings of the lesion study by Shammi and Stuss (1999) suggested a contribution of the PFC to humor processing. The observed humor processing deficits in the present investigation may thus be linked to PFC dysfunction in major depression, as shown by recent studies (Veiel, 1997).

The humor processing deficits of depressed patients in the present investigation were related to reduced mentalizing ability, which also showed significant associations with BDI scores. The findings of the present investigation are consistent with Lee et al. (2005) and Kerr et al. (2003), who reported mentalizing deficits in depression. Intact mentalizing abilities are likely to play an important role in humor processing, because the recipient is assumed to adopt the perspectives of the main protagonists to comprehend the correct punchlines. This assumption is consistent with investigations of humor processing in autism, schizophrenia, alcoholism, and normal aging (Corcoran et al., 1997; Uekermann et al., 2006, 2007b; Winner et al., 1998).

In the present study mentalizing was associated with both funniness ratings and the number of correct punchlines, suggesting that this ability may contribute to both affective and cognitive components of humor processing. In addition to mentalizing ability, executive functions may be of importance. To understand the correct funny punchline, the recipient has to remember the joke context and instructions, compare and evaluate the different alternatives, shift between potential alternative meanings and inhibit incorrect meanings. In the present investigation, set shifting and verbal fluency were significant predictors for the number of correct punchlines. In addition, the number of correct punchlines was related to performance on the working memory task. The finding that depressed patients showed deficits when both the stages of incongruity resolution described in the theory were required (see later) may thus be because of a higher working memory load. These results are consistent with findings from other investigations showing significant correlations between executive functions and the cognitive component of humor processing (Shammi \& Stuss, 1999, 2003; Uekermann et al., 2006, 2007b).

According to incongruity resolution theory (Suls, 1972), two separate stages, incongruity detection and resolution of the incongruity, are needed for the comprehension of correct punchlines. If the other alternatives used in the present study are considered in these terms, the slapstick and illog- 
ical alternatives involve only the first stage, and the logical alternative involves only the second stage. Compared to the healthy control group, patients with major depression in the present study chose more slapstick alternatives, which require only incongruity detection, and more illogical alternatives, which require only resolution of the incongruity. They selected significantly fewer correct punchlines, suggesting inadequate processing when both stages of humor processing are required. These impairments, however, are not specific to major depression. Uekermann et al. (2006, 2007b) reported that fewer correct punchlines were chosen by older people and alcoholics when compared to healthy controls. These deficits were also related to executive functions and mentalizing. The deficits in alcoholic patients can be interpreted in the context of the frontal lobe hypothesis, which asserts a specific vulnerability of the prefrontal cortex to the neurotoxic effects of alcohol (Parsons, 1994). In addition, the frontal lobes have been reported to be disproportionately affected by normal aging (Tisserand \& Jolles, 2003; West \& Covell, 2001). The similarities across the three investigations thus suggest that humor processing and mentalizing deficits can occur across different etiologies involving dysfunction of the prefrontal cortex.

In the light of the reduced funniness ratings made by the depressed patients, an important issue is the question whether sense of humor is affected after the onset of disease, or is present beforehand and associated with a higher risk for depression. This cannot be resolved by the current study, and further studies would therefore be desirable to investigate this issue in individuals who are at a higher risk for developing depression because of a genetic vulnerability.

Another important issue is the question whether the observed deficits in depressed patients may be due to reduced effort. Although this possibility cannot be completely ruled out, the fact that significant differences were not observed for all measures (TMTA and control questions) does not support an interpretation in terms of reduced effort.

In summary, the present study suggested impairment in cognitive and affective components of humor processing in major depression and potential links with mentalizing and executive skills. The results with respect to mentalizing may be of particular relevance in the light of an investigation by Inoue et al. (2006), who reported that depressed patients with mentalizing deficits relapsed significantly more frequently. The importance of humor for the treatment of depression is suggested by a recent investigation in which quality of life scores for depressed patients improved after humor therapy (Walter et al., 2007). It has also been reported (perhaps unsurprisingly) that depressed participants find social interactions less enjoyable than non-depressed participants (Nezlek et al., 2000). Humour and mentalizing may be of critical importance for the enjoyment of social interactions. Moreover, reduced enjoyment in people with major depression may be partly because of mentalizing and humor processing deficits. Thus ability to process humor and appreciate mentalistic perspectives should be given consideration in therapeutic approaches to depression.

\section{ACKNOWLEDGMENTS}

We disclose any financial or other relationships that could be interpreted as a conflict of interest including those (a) with manufacturer(s) of any commercial products(s) and/or provider(s) of commercial services and (b) with any commercial support of the research reported in the manuscript submitted for publication. There are no sources of financial support.

\section{REFERENCES}

Aschenbrenner, S., Tucha, O., \& Lange, K.W. (2000). Regensburger Wortflüssigkeits-Test (RWT). Göttingen, Germany: Hogrefe.

Bäumler, G. (1985). Farbe-Wort-Interferenztest (FWIT) nach J. Stroop (Interference-Word-Interference Test according to J. Stroop). Göttingen, Germany: Hogrefe.

Beck, A.T. (1987). Beck Depression Inventory. San Antonio, TX: The Psychological Corporation.

Bihrle, A.M., Brownell, H.H., Powelson, J.A., \& Gardner, H. (1986). Comprehension of humourous and nonhumourous materials by left and right brain-damaged patients. Brain and Cognition, 5, 399-411.

Brody, A.L., Barsom, M.W., Bota, R.G., \& Saxena, S. (2001). Prefrontal-subcortical and limbic circuit mediation of major depressive disorder. Seminars in Clinical Neuropsychiatry, 6, $102-12$.

Brownell, H.H., Michel, D., Powelson, J., \& Gardner, H. (1983). Surprise but not coherence: Sensitivity to verbal humor in righthemisphere patients. Brain and Language, 18, 20-27.

Corcoran, R., Cahill, C., \& Frith, C.D. (1997). The appreciation of visual jokes in people with schizophrenia: A study of "mentalizing" ability. Schizophrenia Research, 24, 319-327.

Dahl, G. (1986). Reduzierter Wechlser Intelligenztest (Short version of the Wechsler Intelligence Test). Hain, Germany: Meisenheim.

Deaner, S.L. \& McConatha, J.T. (1993). The relation of humor to depression and personality. Psychology Reports, 72, 755-763.

Doody, G.A., Gotz, M., Johnstone, E.C., Frith, C.D., \& Owens, D.G. (1998). Theory of mind and psychoses. Psychological Medicine, 28, 397-405.

Gallagher, H.L., Happe, F., Brunswick, N., Fletcher, P.C., Frith, U., \& Frith, C.D. (2000). Reading the mind in cartoons and stories: An fMRI study of 'theory of mind' in verbal and nonverbal tasks. Neuropsychologia, 38, 11-21.

Goel, V. \& Dolan, R.J. (2001). The functional anatomy of humor: Segregating cognitive and affective components. Nature Neuroscience, 4, 237-238.

Gotlib, I.H. \& Lee, C.M. (1989). The social functioning of depressed patients: A longitudinal assessment. Journal of Social and Clinical Psychology, 8, 223-237.

Heath, R.L. \& Blonder, L.X. (2005). Spontaneous humor among right hemisphere stroke survivors. Brain and Language, 93, 267-276.

Inoue, Y., Tonooka, Y., Yamada, K., \& Kanba, S. (2004). Deficiency of theory of mind in patients with remitted mood disorder. Journal of Affective Disorders, 82, 403-409.

Inoue, Y., Yamada, K., \& Kanba, S. (2006). Deficit in theory of mind is a risk for relapse of major depression. Journal of Affective Disorders, 95, 125-127.

Kerr, N., Dunbar, R.I., \& Bentall, R.P. (2003). Theory of mind deficits in bipolar affective disorder. Journal of Affective Disorders, 73, 253-259. 
Lee, L., Harkness, K.L., Sabbagh, M.A., \& Jacobson, J.A. (2005). Mental state decoding abilities in clinical depression. Journal of Affective Disorders, 86, 247-258.

Levendosky, A.A., Okun, A., \& Parker, J.G. (1995). Depression and maltreatment as predictors of social competence and social problem-solving skills in school-age children. Child Abuse and Neglect, 19, 1183-1195.

Mikhailova, E.S., Vladimirova, T.V., Iznak, A.F., Tsusulkovskaya, E.J., \& Sushko, N.V. (1996). Abnormal recognition of facial expression of emotions in depressed patients with major depression disorder and schizotypal personality disorder. Biological Psychiatry, 40, 697-705.

Nezlek, J.B., Hampton, C.P., \& Shean, G.D. (2000). Clinical depression and day-to-day social interaction in a community sample. Journal of Abnormal Psychology, 109, 11-19.

Parsons, O.A. (1994). Neuropsychological measures and eventrelated potentials in alcoholics: Interrelationships, long-term reliabilities, and prediction of resumption of drinking. Journal of Clinical Psychology, 50, 37-46.

Pien, D. \& Rothbart, M.K. (1976). Incongruity and resolution in children's humor. A reexamination. Child Development, 47, 966-971.

Premack, D. \& Woodruff, G. (1978). Does the chimpanzee have a theory of mind? Behavioral and Brain Sciences, 4, 515-526.

Reitan, R.M. (1992). Trail Making Test: Manual and administration for scoring. South Tucson, AZ: Reitan Neuropsychology Laboratory.

Ruch, W. (1981). Witzebeurteilung und Persönlichkeit: Eine trimodale Analyse. Zeitschrift für Differenzielle und Diagnostische Psychologie, 2, 253-273.

Ruch, W. \& Hehl, F.J (1984). Individual differences in sense of humor: A factor analytic approach. (paper presented at the 4th International Congress on humor, Tel Aviv, Israel, 1984).

Ruch, W. \& Hehl, F.J. (1986). Conservatism as a predictor of responses to humor: II. The location of sense of humor in a comprehensive attitude space. Personality and Individual Differences, 7, 861-874.

Saß, H., Wittchen, H.U., \& Zaudig, M. (2003). Diagnostisches und statistisches Manual psychischer Störungen (DSM-IV) (Diagnostical and Statistical Manual of Mental Disorders). Göttingen, Germany: Hogrefe.

Shammi, P. \& Stuss, D.T. (1999). Humour appreciation: A role of the right frontal lobe. Brain, 122, 657-666.

Shammi, P. \& Stuss, D.T. (2003). The effects of normal aging on humor appreciation. Journal of the International Neuropsychological Society, 9, 855-863.

Shultz, T.R. (1972). The role of incongruity and resolution in children's appreciation of cartoon humor. Journal of Experimental and Child Psychology, 13, 456-477.

Shultz, T.R. \& Horibe, F. (1974). Development of the Appreciation of verbal jokes. Developmental Psychology, 10, 13-20.

Shultz, T.R. \& Pilon, R. (1973). Development of the Ability to Detect Linguistic Ambiguity. Child Development, 44, 728-733.

Singer, T. (2006). The neuronal basis and ontogeny of empathy and mind reading: Review of literature and implications for future research. Neuroscience and Biobehavioral Reviews, 30, 855-863.

Stuss, D.T., Gallup, G.G. Jr., \& Alexander, M.P. (2001). The frontal lobes are necessary for "theory of mind". Brain, 24, 279-886.

Suls, J.M. (1972). A two-stage model for the appreciation of jokes and cartoons. In J.H. Goldstein \& P.E. McGhee (Eds.), The
Psychology of Humour: Theoretical perspectives and empirical issues. New York: Academic Press.

Suls, J.M. (1983). Cognitive processes in humor appreciation. In P.E. McGhee \& J.H. Goldstein (Eds.), Handbook of humor research. New York: Springer.

Surguladze, S.A., Young, A.W., Senior, C., Brebion, G., Travis, M.J., \& Phillips, M.L. (2004). Recognition accuracy and response bias to happy and sad facial expressions in patients with major depression. Neuropsychology, 18, 212-218.

Thorson, J.A., Powell, F.C., Sarmany-Schuller, I., \& Hampes, W.P. (1997). Psychological health and sense of humor. Journal of Clinical Psychology, 53, 605-619.

Thorson, J.A. \& Powell, F.C. (1994). Depression and sense of humor. Psychological Reports, 75, 1473-1474.

Tisserand, D.J. \& Jolles, J. (2003). On the involvement of prefrontal networks in cognitive aging. Cortex, 39, 1107-1128.

Uekermann, J., Channon, S., \& Daum, I. (2006). Humour processing, mentalizing and executive function in normal aging. Journal of the International Neuropsychological Society, 12, 184-191.

Uekermann, J., Channon, S., \& Daum, I. (2007a). Towards a cognitive and social neuroscience of humor processing. Social Cognition, in press.

Uekermann, J., Channon, S., Winkel, K., Schlebusch, P., Trenckmann, U., \& Daum, I. (2007b). Theory of mind, humor processing and executive function in alcoholism. Addiction, 102, 232-240.

Varga, A.C. (1984). Declaration of Helsinki. Adopted by the 18th World Medical Assembly in Helsinki, Finland, and revised by the 29th World Assembly in Tokyo, 1971. In The Main Issue in Bioethics, revised edition. New York: Paulist Press.

Veiel, H.O. (1997). A preliminary profile of neuropsychological deficits associated with major depression. Journal of Clinical and Experimental Neuropsychology, 19, 587-603.

Vollm, B.A., Taylor, A.N., Richardson, P., Corcoran, R., Stirling, J., McKie, S., Deakin, J.F. \& Elliott, R. (2006). Neuronal correlates of theory of mind and empathy: A functional magnetic resonance imaging study in a nonverbal task. Neuroimage, 29, 90-98.

Walter, M., Hanni, B., Haug, M., Amrhein, I., Krebs-Roubicek, E., Muller-Spahn, F., \& Savaskan, E. (2007). Humour therapy in patients with late-life depression or Alzheimer's disease: A pilot study. International Journal of Geriatric Psychiatry, 22, 77-83.

Wapner, W., Hamby, S., \& Gardner, H. (1981). The role of the right hemisphere in the apprehension of complex linguistic materials. Brain and Language, 14, 15-33.

Wechsler, D. (1997). Wechsler Memory Scale (3rd ed.). San Antonio, TX: Harcourt Assessment.

West, R. \& Covell, E. (2001). Effects of aging on event related neural activity related to prospective memory. Neuroreport, 12, 2855-2858.

Wild, B., Rodden, F.A., Grodd, W., \& Ruch, W. (2003). Neural correlates of laughter and humor. Brain, 126, 2121-2138.

Winner, E., Brownell, H., Happe, F., Blum, A., \& Pincus, D. (1998). Distinguishing lies from jokes: Theory of mind deficits and discourse interpretation in right hemisphere brain-damaged patients. Brain and Language, 62, 89-106.

Zakzanis, K.K., Leach, L., \& Kaplan, E. (1998). On the nature and pattern of neurocognitive function in major depressive disorder. Neuropsychiatry, Neuropsychology and Behavioral Neurology, 11, 111-119. 